\title{
There is no difference in outcome between laparoscopic and open surgery for rectal cancer: a systematic review and meta-analysis on short- and long-term oncologic outcomes
}

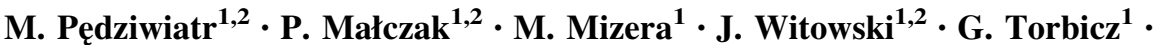 \\ P. Major ${ }^{1,2} \cdot$ M. Pisarska ${ }^{1,2} \cdot$ M. Wysocki ${ }^{1,2} \cdot$ A. Budzyński ${ }^{1,2}$
}

Received: 28 April 2017 / Accepted: 4 July 2017/Published online: 9 August 2017

(c) The Author(s) 2017. This article is an open access publication

\begin{abstract}
Background Until recently there has been little data available about long-term outcomes of laparoscopic rectal cancer surgery. But new randomized controlled trials regarding laparoscopic colorectal surgery have been published. The aim of this study was to compare the short- and long-term oncologic outcomes of laparoscopy and open surgery for rectal cancer through a systematic review of the literature and a meta-analysis of relevant RCTs.

Methods A systematic review of Medline, Embase and the Cochrane library from January 1966 to October 2016 with a subsequent meta-analysis was performed. Only randomized controlled trials with data on circumferential resection margins were included. The primary outcome was the status of circumferential resection margins. Secondary outcomes included lymph node yield, distal resection margins, disease-free and overall survival rates for 3 and 5 years and local recurrence rates.

Results Eleven studies were evaluated, involving a total of 2018 patients in the laparoscopic group and 1526 patients in the open group. The presence of involved circumferential margins was reported in all studies. There were no
\end{abstract}

M. Pędziwiatr and P. Małczak are equal first authors.

Electronic supplementary material The online version of this article (doi:10.1007/s10151-017-1662-4) contains supplementary material, which is available to authorized users.

M. Pędziwiatr

michal.pedziwiatr@uj.edu.pl

1 2nd Department of General Surgery, Jagiellonian University Medical College, Kopernika 21, 31-501 Kraków, Poland

2 Centre for Research, Training and Innovation in Surgery (CERTAIN Surgery), Kraków, Poland statistically significant differences in the number of positive circumferential margins between the laparoscopic group and open group, RR 1.16, 95\% CI 0.89-1.50 and no significant differences in involvement of distal margins (RR 1.13 95\% CI 0.35-3.66), completeness of mesorectal excision (RR 1.22, 95\% CI 0.82-1.82) or number of harvested lymph nodes (mean difference $=-0.01,95 \% \mathrm{CI}$ -0.89 to 0.87 ). Disease-free survival rates at 3 and 5 years were not different ( $p=0.26$ and $p=0.71$ respectively), and neither were overall survival rates $(p=0.19$ and $p=0.64$ respectively), nor local recurrence rates (RR 0.88 , 95\% CI 0.63-1.23).

Conclusions Laparoscopic surgery for rectal cancer is associated with similar short-term and long-term oncologic outcomes compared to open surgery. The oncologic quality of extracted specimens seems comparable regardless of the approach used.

Keywords Laparoscopy · Total mesorectal excision · Rectal cancer - Circumferential resection margin . Survival $\cdot$ Local recurrence $\cdot$ Meta-analysis

\section{Introduction}

There has been a constant increase in the incidence of colorectal cancer. Currently it is the most common gastrointestinal malignancy worldwide [1]. Approximately one-third of all large bowel cancers are located in the rectum [1]. So far, the primary treatment option for rectal adenocarcinoma remains surgery, supported by neoadjuvant and adjuvant therapy $[2,3]$.

Over the last two decades, a trend towards minimally invasive surgery in the treatment of rectal cancer has been observed [4]. In selected patients, laparoscopic surgery has 
been reported to achieve better short-term outcomes, which include: lower postoperative morbidity, reduced intraoperative blood loss, less pain, faster recovery and better quality of life [5-8]. Although there is much evidence supporting laparoscopy in terms of perioperative parameters, little is known of the influence of this surgical technique on long-term outcomes. It is generally accepted that, from the oncologic perspective, disease-free survival is considered a primary endpoint in the assessment of treatment quality in rectal cancer. The most important surgical factors related to long-term oncologic results are clear resection margins and completeness of mesorectal excision. So far, several randomized trials comparing laparoscopic and open surgery have been conducted. However, in most of them the oncologic outcomes are not set as primary endpoints (thus creating potential bias related to underpowering) or full resection details are not reported. Moreover, the evidence on survival after open versus laparoscopic surgery within a randomized controlled trial (RCT) environment is sparse, with these results from highquality RCTs only recently published [9-11].

Our aim was to evaluate the effectiveness of laparoscopy and open surgery for rectal cancer by systematically reviewing the available literature and conducting a metaanalysis of RCTs comparing short-term and long-term oncologic outcomes.

\section{Materials and methods}

\section{Search strategy}

In October 2016, a search was conducted by three teams, with two researchers in each, of Medline, Embase and the Cochrane Library, covering a period from January 1966 to October 2016. The search had no language limitations, so that the review would be as comprehensive as possible. A full search strategy for strategy for OVID platform is available in supplement 1. Reference lists of relevant publications were assessed for additional studies. Furthermore, references from other systematic reviews or metaanalyses on the subject were searched.

A study was included when it comprised adult patients, rectal surgery for malignancy and reported on the circumferential resection margin (CRM) status. Only RCTs were included. Studies were excluded if they were not full-text papers, were not RCTs or did not report data on CRM. Studies that fulfilled all the criteria were eligible for further evaluation.

All teams identified and selected citations from the search independently. In case of doubt about inclusion, an attempt was made to reach a consensus within the team. If no consensus was possible, a decision was made by a third member of the group outside that team. Data from included studies were extracted independently by all teams. The study quality and risk of bias was assessed using the Cochrane Collaboration's tool for assessing risk of bias.

\section{Outcome measures}

The primary outcome measures of this systematic review were involved CRM status. Secondary outcome measures were distal resection margin, completeness of mesorectal excision, total number of harvested lymph nodes, 3-year disease-free, 5-year disease-free and overall survival rate as well as local recurrence rate. The quality of mesorectal dissection was classified according to Nagtegaal et al. [12]. For the purpose of subsequent meta-analysis, similarly to Nagtegaal's original paper 'complete' and 'nearly complete' mesorectal excisions were grouped together as 'complete' and were compared with 'incomplete' mesorectal excisions.

\section{Statistical analysis}

Analysis was performed using RevMan 5.3 (freeware from the Cochrane Collaboration). Statistical heterogeneity and inconsistency were measured using Cochran's $Q$ and $I^{2}$, respectively. Qualitative outcomes from individual studies were analysed to assess individual and pooled risk ratios (RR) with pertinent 95\% confidence intervals (CI) favouring the minimally invasive approach over open surgery and by means of the Mantel-Haenszel fixed-effects method in the presence of low or moderate statistical inconsistency $\left(I^{2} \leq 10 \%\right)$ and by means of a random-effects method (which better accommodates clinical and statistical variations) in the case of high statistical inconsistency $\left(I^{2}>10 \%\right)$. For positive outcomes RR was calculated for 'non-event' occurrence. When the study included medians and interquartile ranges, we calculated the mean \pm standard deviation (SD) using a method proposed by Hozo et al. [13]. Weighted mean differences (WMD) with $95 \% \mathrm{CI}$ are presented for quantitative variables using the inverse variance fixed-effects or randomeffects method. Statistical significance was observed with a two-tailed 0.05 level for hypothesis and with 0.10 for heterogeneity testing, while unadjusted $p$ values were reported accordingly. This study was performed according to the Preferred Reporting Items for Systematic Reviews and Meta-Analyses (PRISMA) guidelines.

\section{Results}

The initial reference search yielded 3446 articles. After removing 1721 duplicates, 1725 articles were evaluated through titles and abstracts. This produced 224 papers 


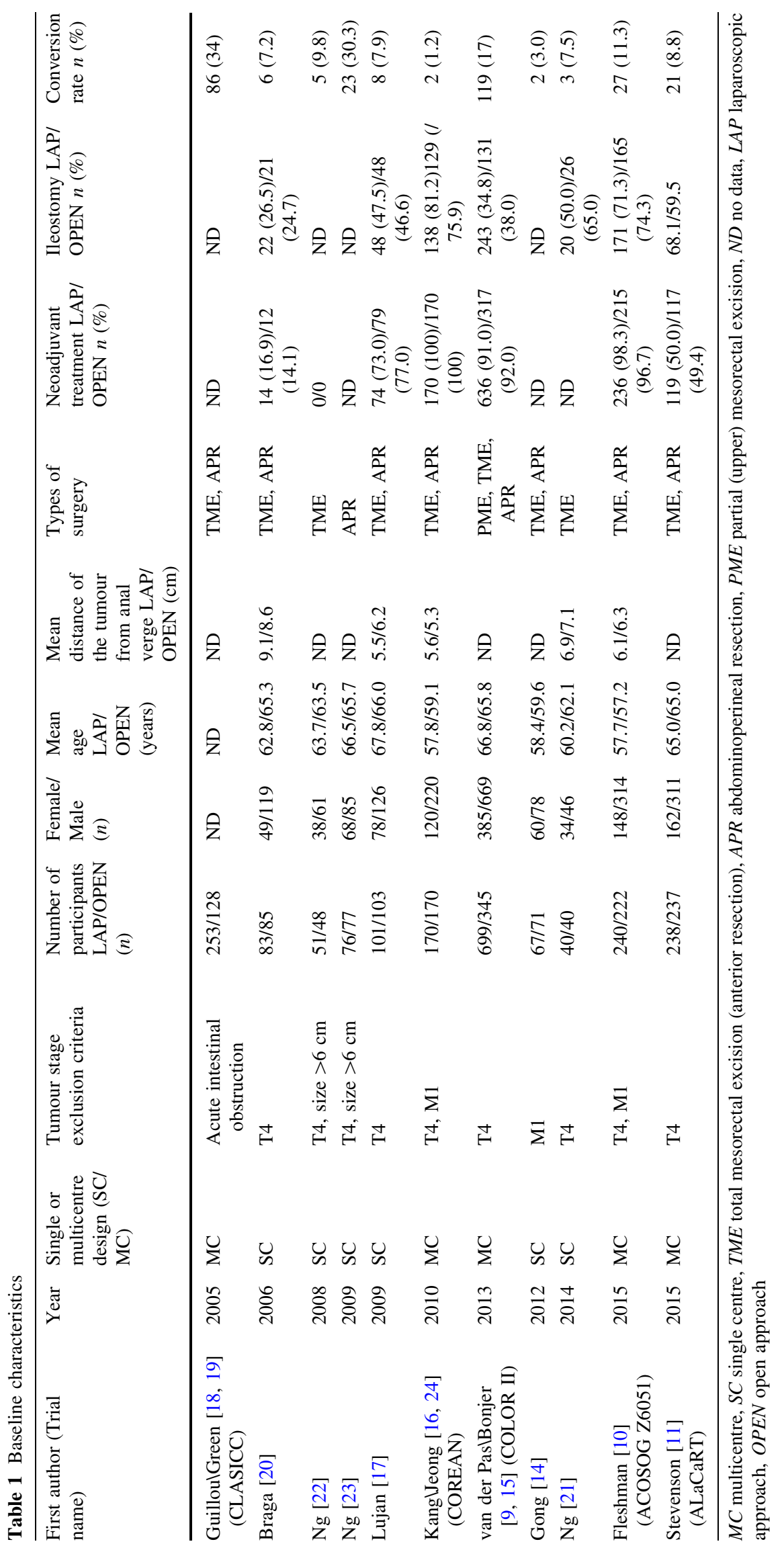




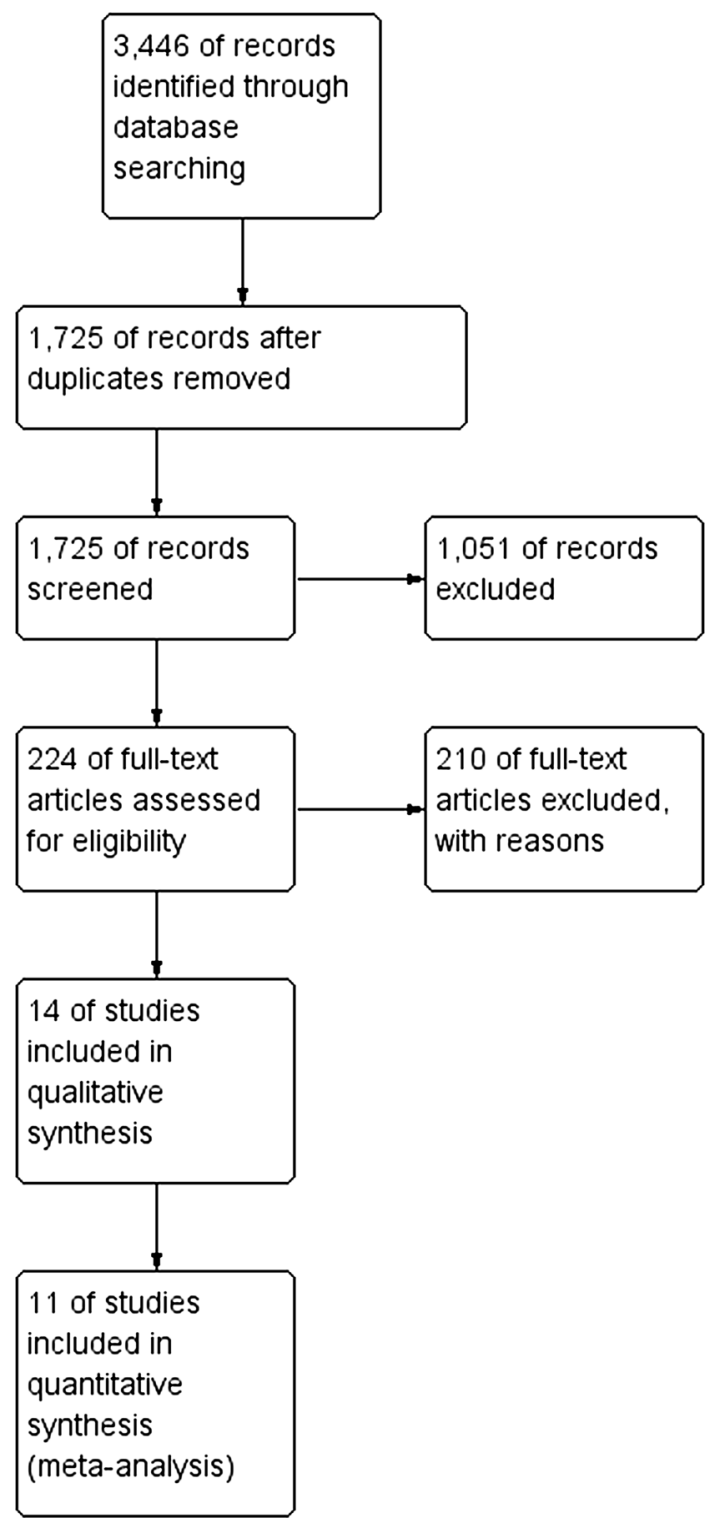

Fig. 1 PRISMA flowchart

suitable for full-text review, of which 14 studies met the eligibility criteria [9-11, 14-24]. There were 3 trials (COLOR II, COREAN, CLASICC) in which results were reported in more than one paper. Papers from the same trial were analysed as one study, so that a total of 11 studies were analysed; 2018 patients in the laparoscopic group and 1526 patients in the open group (Table 1). The literature search and study selection is summarized in Fig. 1. Risk of bias in the studies is assessed in Fig. 2. In general, the risk of bias in the studies was low. Due to the nature of the treatment, the blinding of participants and personnel was impossible to perform. The outcome assessment was the main source of bias as most of the studies did not clearly define how and by whom it was performed. The paper with the most potential for bias, Gong et al. [14], has been included in the analysis as it had little impact on heterogeneity.

Involved CRMs were reported in all 11 studies. None of the analysed studies showed differences in CRM status between the laparoscopic and open approach. Overall, there were no statistically significant differences in the number of positive CRMs between the laparoscopic group $(137 / 1847(7.42 \%))$ and the open group (83/1448 (5.73\%)), RR 1.16, 95\% CI $0.89-1.50, p$ for effect $=0.27, p$ for heterogeneity $=0.71, I^{2}=0 \%$ (Fig. 3).

Data on involved distal margins were provided in $4 / 11$ studies. None of the analysed studies showed differences in positive distal margins between the laparoscopic and open approach. The analysis revealed no significant differences in distal margin positivity: $6 / 662(0.91 \%)$ in the laparoscopic group versus $5 / 645(0.78 \%)$ in the open group, RR $1.1395 \%$ CI $0.35-3.66, p$ for effect $=0.84, p$ for heterogeneity $=0.59, I^{2}=0 \%$ (Fig. 4).

The data on the completeness of mesorectal excision were reported in 5/11 papers, involving 2339 patients. In 4 papers, the classification proposed by Nagtegaal et al. was used. In the fifth paper, by $\mathrm{Ng}$ et al. [21], mesorectal excision was described as complete or incomplete. In the 4 papers which used complete/nearly complete/incomplete classification, complete mesorectal excision occurred in $1093 / 1308(83.56 \%)$ of laparoscopic cases and 827/951 $(86.96 \%)$ of open procedures. Nearly complete excision was recorded in 161/1308 (12.30\%) laparoscopic and $89 / 951$ (9.36\%) open procedures. Incomplete excision was recorded in 54/1308 (4.13\%) laparoscopic and 333/951 $(3.47 \%)$ open procedures. The meta-analysis of all 5 studies reporting completeness of mesorectal excision (complete was combined with nearly complete and compared with incomplete as in Nagtegaal's classification) revealed no significant differences among the studies: 1290/1348 (95.69\%) versus 953/991 (96.17\%), RR 1.22, $95 \%$ CI $0.82-1.82, p$ for effect $=0.33, p$ for heterogeneity $=0.6, I^{2}=0 \%$ (Fig. 5).

The number of harvested lymph nodes was reported in 9 studies. Kang et al. and van der Pas et al. reported open procedures harvesting a greater number of lymph nodes, whereas Lujan et al. reported the opposite [15, 17, 24]. The remaining studies did not present statistically significant data. Overall, the analysis revealed no statistically significant differences among the studied groups, mean difference $=-0.01,95 \% \mathrm{CI}-0.89$ to $0.87, p$ for effect $=0.98$, $p$ for heterogeneity $=0.001, I^{2}=69 \%$ (Fig. 6).

The disease-free 3-year survival rate was reported in 5 papers, whereas an overall 3-year survival rate was reported in 6 . There were no significant variations among the groups $[p=0.26$ and $p=0.18$ (Figs. 7, 8)]. Five-year survival and 5-year disease-free survival rates were each reported in by 5 authors. There were no statistically 


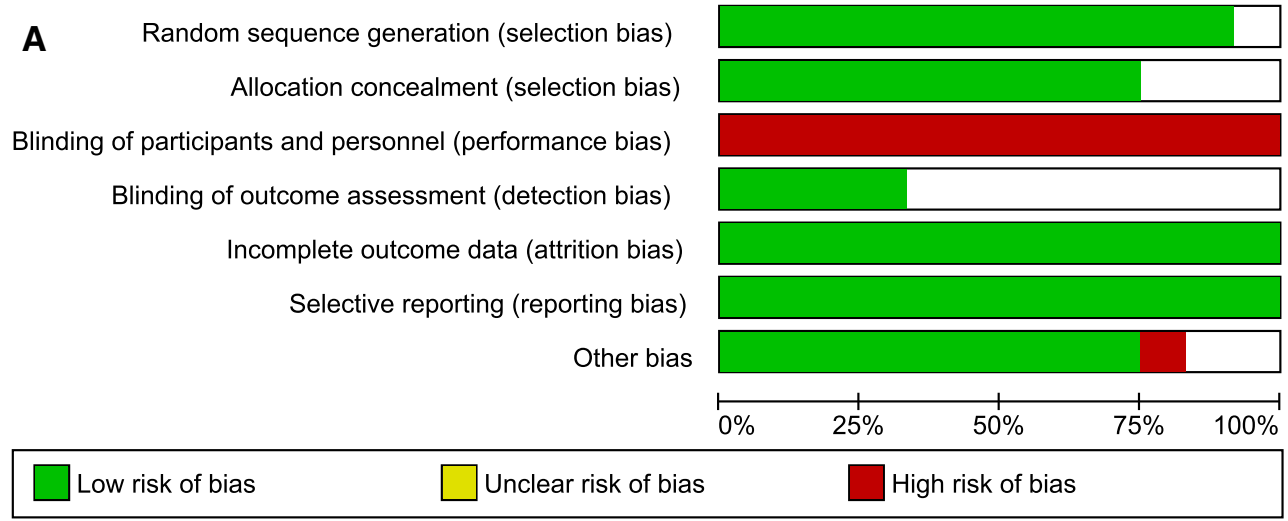

B

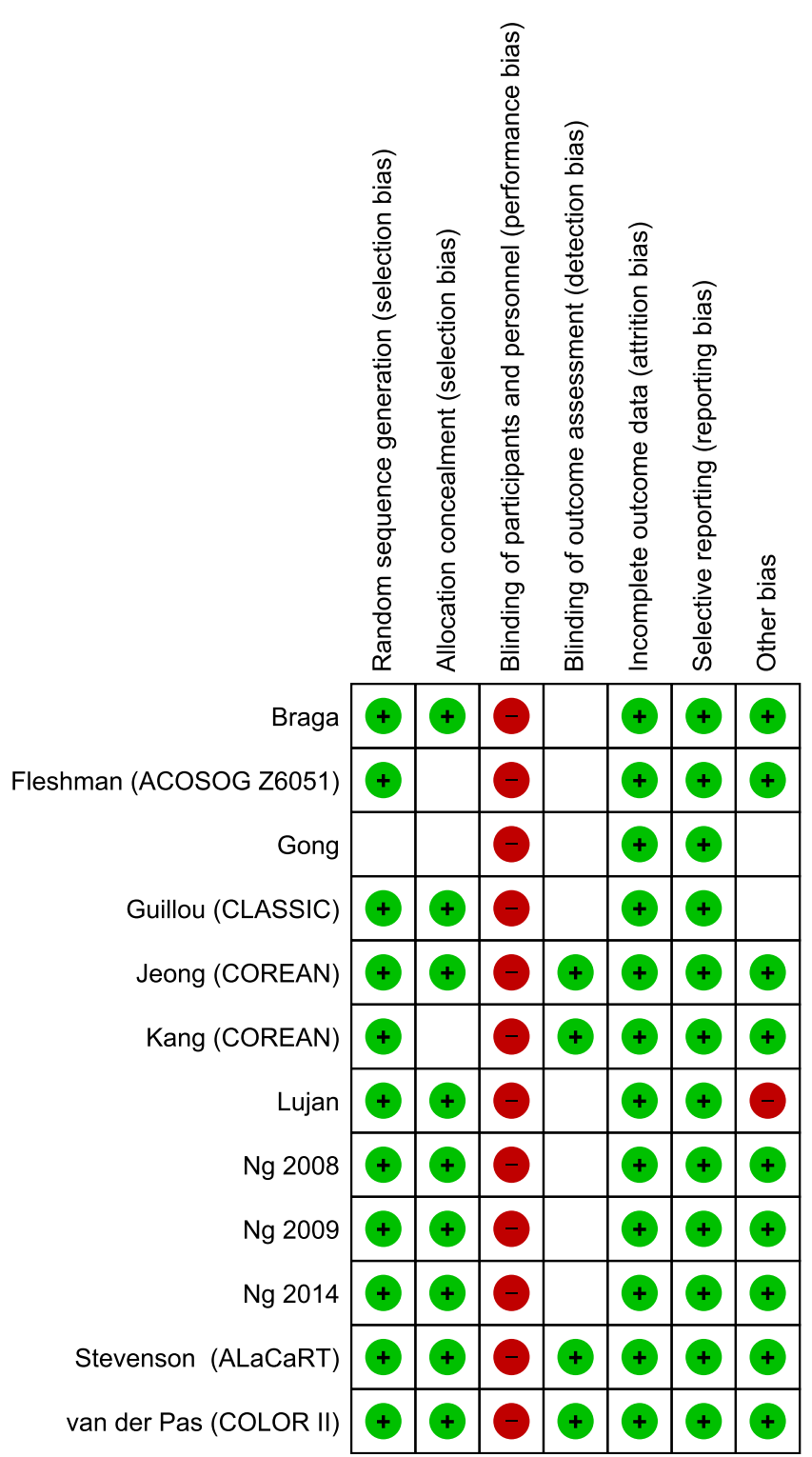

Fig. 2 Risk of bias summary 


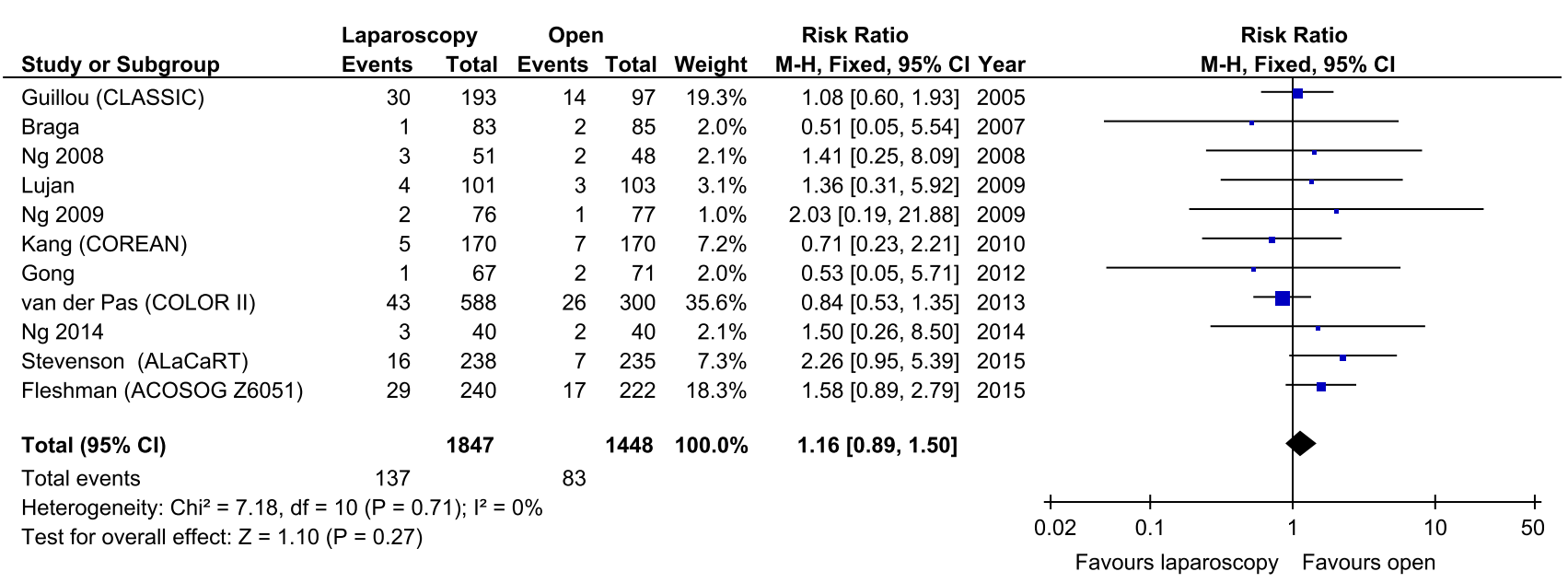

Fig. 3 Pooled estimates of involved circumferential resection margins comparing laparoscopy and open surgery. $C I$ confidence interval, $d f$ degrees of freedom, $R R$ risk ratio

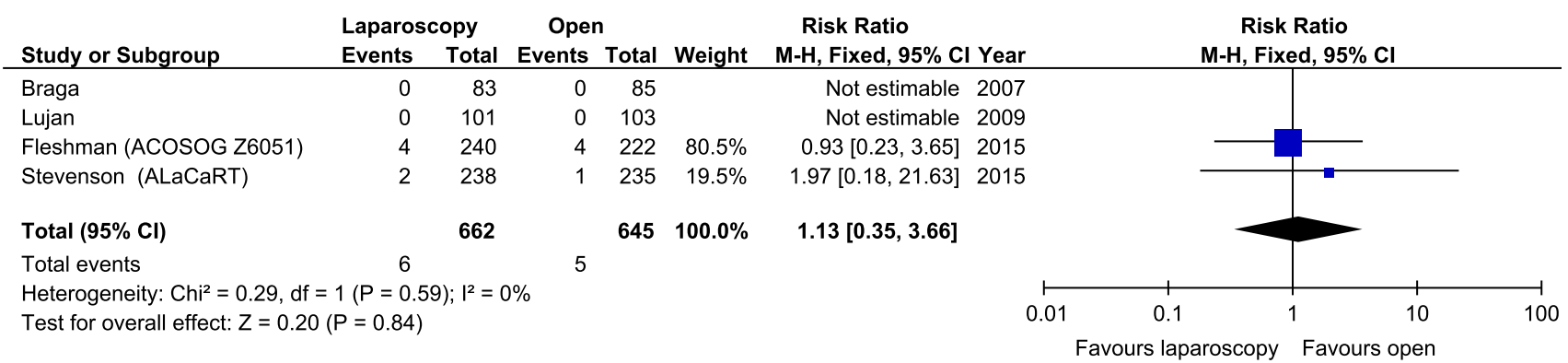

Fig. 4 Pooled estimates of involved distal margins comparing laparoscopy and open surgery. $C I$ confidence interval, $d f$ degrees of freedom, $R R$ risk ratio

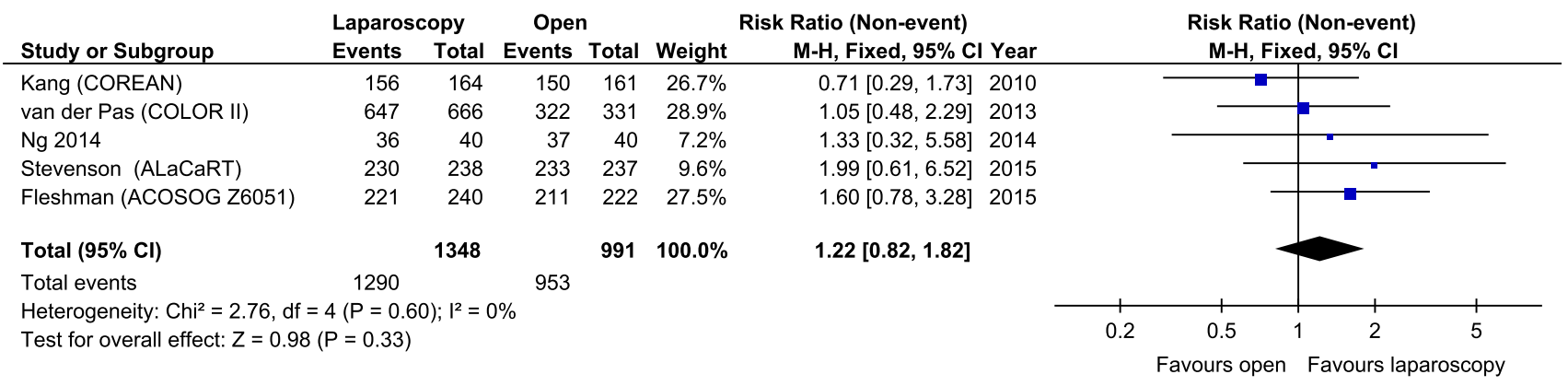

Fig. 5 Pooled estimates of completeness of mesorectal excision comparing laparoscopy and open surgery. $C I$ confidence interval, $d f$ degrees of freedom, $R R$ risk ratio

significant differences in 5-year survival rate, $p=0.64$. No differences were found in terms of disease-free survival either, $p=0.71$ (Figs. 9, 10).

The local recurrence rate was reported in 8/11 studies. It ranged from 2.35 to $9.88 \%$ in the laparoscopic group, and $4.47-11.11 \%$ in the open group. There were no statistically significant variations among the studied groups, RR 0.88 , $95 \%$ CI $0.63-1.23, p$ for effect $=0.45, p$ for heterogeneity $=0.79, I^{2}=0 \%$ (Fig. 11).

\section{Discussion}

We found no difference in circumferential resection margin involvement between laparoscopic and open surgery for rectal cancer. Not difference was found in any other oncological parameter, nor any difference in disease-free or overall survival by 5 years.

The quality of included studies was mostly high and very high. For obvious reasons, none of them blinded the participants and only 5 studies blinded outcome assessors. 


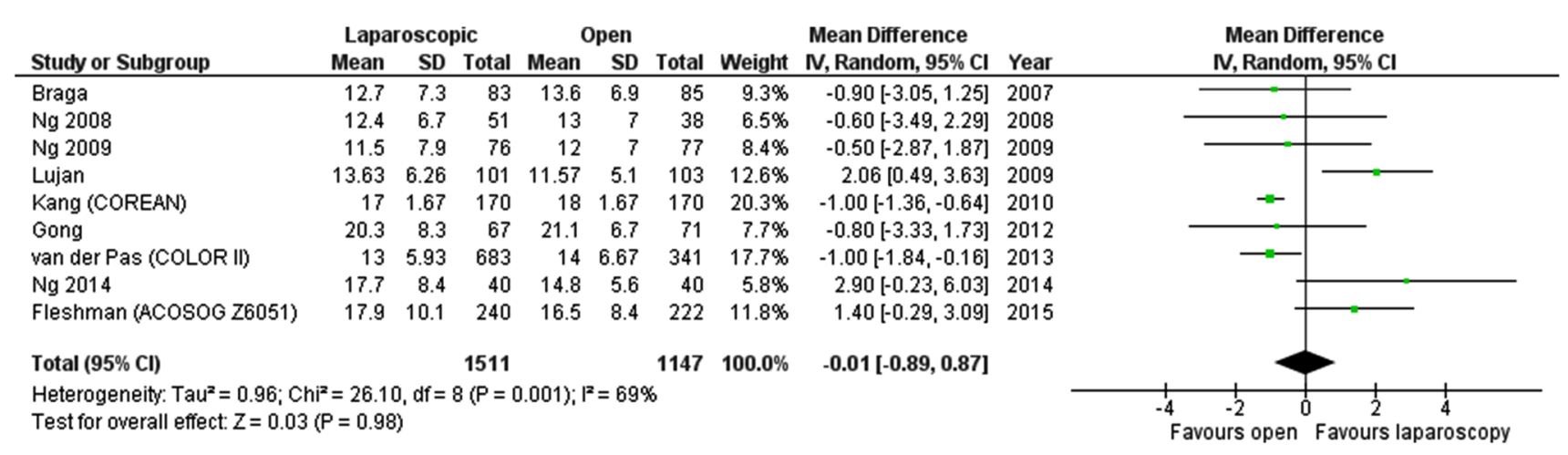

Fig. 6 Pooled estimates of harvested lymph node yield comparing laparoscopy and open surgery. $C I$ confidence interval, $d f$ degrees of freedom, $R R$ risk ratio

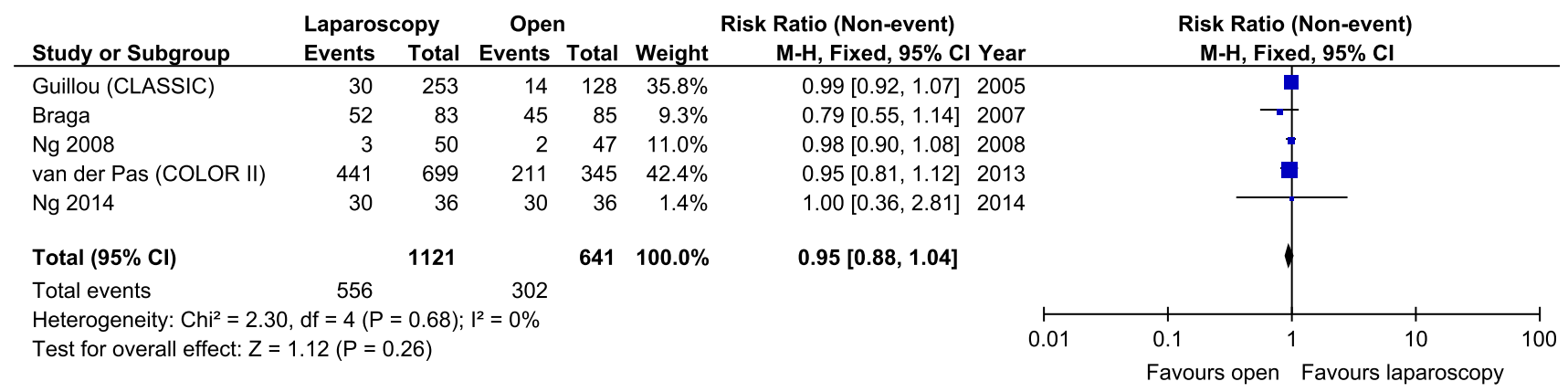

Fig. 7 Pooled estimates of 3-year disease-free survival rate comparing laparoscopy and open surgery. $C I$ confidence interval, $d f$ degrees of freedom, $R R$ risk ratio

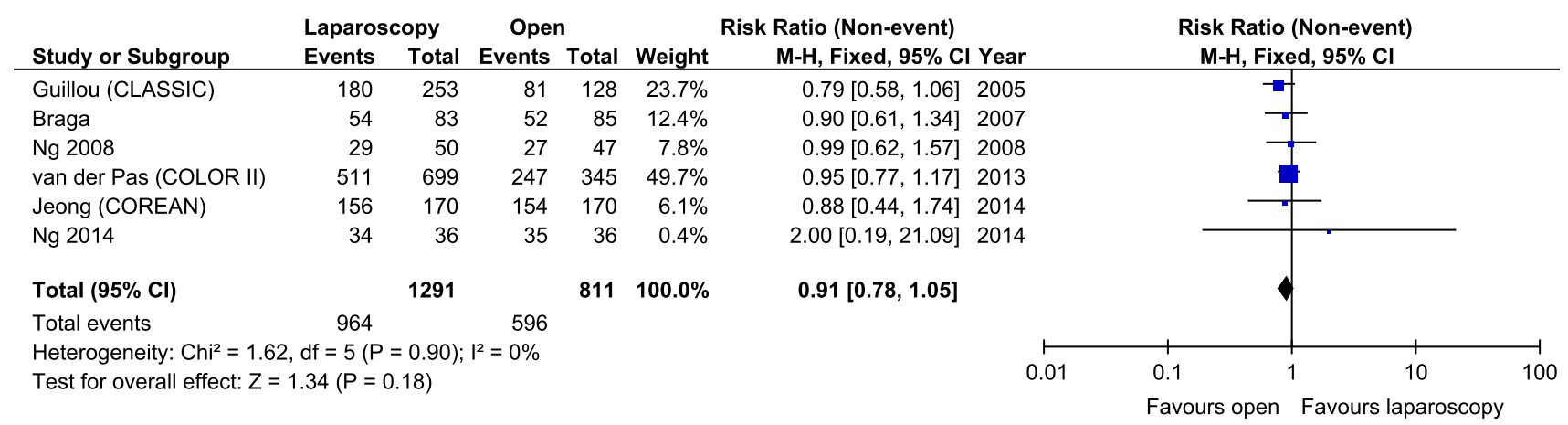

Fig. 8 Pooled estimates of 3-year overall survival rate comparing laparoscopy and open surgery. $C I$ confidence interval, $d f$ degrees of freedom, $R R$ risk ratio

Although this may create potential bias, one should remember that in surgical RCTs, blinding is either impossible or at the very least, difficult. All analysed studies included groups of patients undergoing laparoscopic resection, no robotic surgery was involved, although there are currently several ongoing trials comparing laparoscopic with robotic surgery registered at clinicaltrials.gov (NCT01736072 (ROLARR), NCT01130233, NCT01985698 (RLOAPR), NCT01591798, NCT02673177 (TRVL), NCT02817126).

The involved CRM rate varied among studies between 1.2 and $15.5 \%$ in the laparoscopic group and $1.3-14.43 \%$ in the open group. However, there was no overall difference between laparoscopic and open surgery and heterogeneity was low. Differences in CRM involvement between studies may suggest that the quality of surgery varied or (less probably) there were differences in pathologic assessment (there were no pre-operative differences in $\mathrm{T}$ stage or use of neoadjuvant therapy between groups). In our meta-analysis, the completeness of total mesorectal excision was similar regardless of the technique used. In a recent meta-analysis by Martínez-Pérez et al. [25], a difference in completeness of mesorectal excision was found favouring open surgery. More studies were included for 


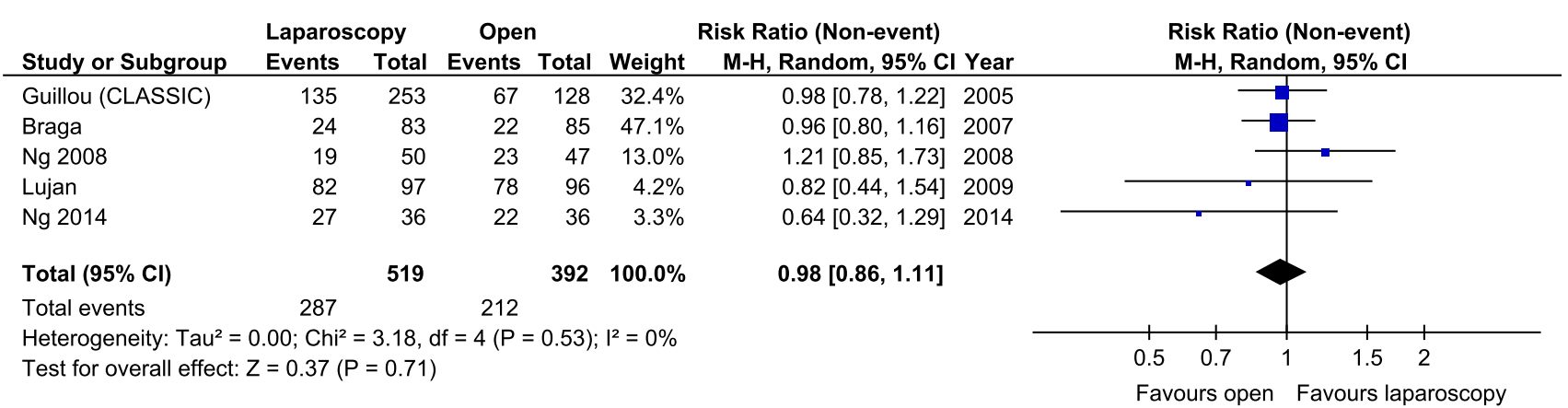

Fig. 9 Pooled estimates of 5-year disease-free survival rate comparing laparoscopy and open surgery. $C I$ confidence interval, $d f$ degrees of freedom, $R R$ risk ratio

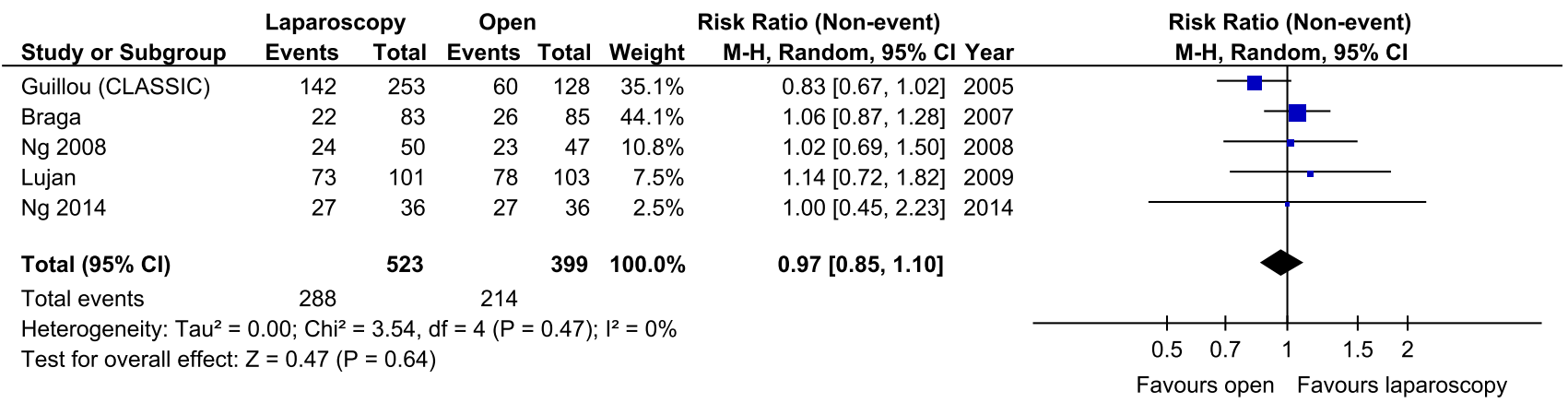

Fig. 10 Pooled estimates of 5-year overall survival rate comparing laparoscopy and open surgery. $C I$ confidence interval, $d f$ degrees of freedom, $R R$ risk ratio

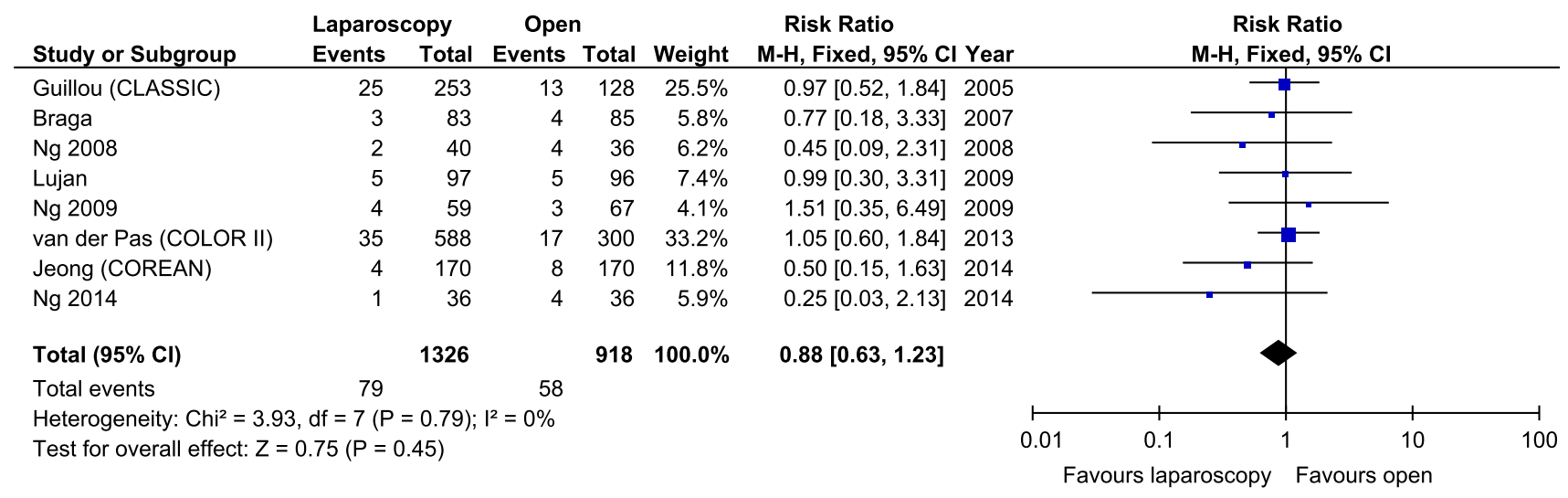

Fig. 11 Pooled estimates of local recurrence rate comparing laparoscopy and open surgery. $C I$ confidence interval, $d f$ degrees of freedom, $R R$ risk ratio

data extraction in our review and we grouped together 'complete' and 'nearly complete' resections while Martínez-Pérez et al. compared 'complete' resections with a group of flawed excisions ('nearly complete' combined with 'incomplete'). More data are needed to fully establish whether there are differences in overall survival between complete and nearly complete mesorectal excisions.

Abbas et al. [26] highlighted issues that might or might not be relevant to short- and long-term oncologic outcomes in laparoscopic rectal surgery. It was suggested that laparoscopy may be inferior to the open approach due to technical limitations leading to a so-called fulcrum/coning effect during dissection, resulting in positive CRM or incomplete mesorectal excision more often in lower rectal cancers. However, our review we did not find differences in CRM involvement, but only 1 study fully analysed the outcomes in low rectal cancers [15], where statistically different rates of CRM involvement were found in patients 
with cancer of the lower third of the rectum and interestingly, worse outcomes were observed in the open surgery group (22\% involved CRMs in the open group and $9 \%$ in laparoscopic group). Certainly, a positive CRM strongly correlates with the height of the tumour [15, 27, 28]. Because of high CRM involvement in low rectal cancers, a novel bottom-up transanal total mesorectal excision has been proposed and currently a multicentre RCT COLOR III trial (NCT02736942) has started to fully assess the oncologic benefits of this approach (estimated primary completion date: May 2020) [29]. There were also differences in conversion rates among studies (1-34\%), which confirms the difficulty of the laparoscopic technique and underlines issues with its standardization. High conversion rates are associated with the learning curve and the surgical unit's experience as well as with tumour stage, which may contribute to worse perioperative outcomes and may also influence survival, although evidence is lacking to draw firm conclusions [30-32].

The number of harvested lymph nodes was similar in the laparoscopic and open group. However, lymph node yield is dependent on many factors such as the tumour itself, the patient, neoadjuvant radiochemotherapy, pathologic assessment [33] and, last but not least, the surgeon [34].

Most importantly, operative technique has no impact on long-term outcomes suggesting that, given the amount of data available further RCTs comparing the laparoscopic and open approach in terms of oncologic outcomes may not be required.

The quality of data in this review has several limitations. In practically all included studies long-term outcomes were not set as a primary endpoint; therefore, most studies were probably underpowered for this parameter. In addition, in most of them involved CRM was used as a universal marker of non-radical operation. However, there is agreement that any involved margin is associated with poor survival. Since distal margins (length and involvement) were not reported in most studies, we were not able to fully assess the R0 resection rate in the analysed groups. According to Parmar et al. [35] in studies involving time to event (survival-type) data, the most appropriate statistics to use are the log hazard ratio and its variance. However, this was not explicitly presented for included studies and we had to compare data after 3 and 5 years post-surgery. Surgeon experience and hospital volume in rectal surgery are important factors influencing outcomes but in this review surgeon experience was not analysed [36-38].

In conclusion, this systematic review with a meta-analysis showed that laparoscopic surgery for rectal cancer is associated with similar short-term and long-term oncologic outcomes compared to open surgery. The oncologic quality of specimens seems comparable regardless of the approach used.

\section{Compliance with ethical standards}

Conflict of interest The authors declare that they have no conflict of interest.

Ethical approval This article does not contain any studies with human participants or animals performed by any of the authors.

Informed consent For this type of study formal consent is not required.

Open Access This article is distributed under the terms of the Creative Commons Attribution 4.0 International License (http://crea tivecommons.org/licenses/by/4.0/), which permits unrestricted use, distribution, and reproduction in any medium, provided you give appropriate credit to the original author(s) and the source, provide a link to the Creative Commons license, and indicate if changes were made.

\section{References}

1. Brenner H, Bouvier AM, Foschi R, Hackl M, Larsen IK, Lemmens V et al (2012) Progress in colorectal cancer survival in Europe from the late 1980s to the early 21st century: the EUROCARE study. Int J Cancer 131(7):1649-1658

2. van de Velde CJ, Boelens PG, Borras JM, Coebergh JW, Cervantes A, Blomqvist L et al (2014) EURECCA colorectal: multidisciplinary management: European consensus conference colon \& rectum. Eur J Cancer 50(1):1.e-e34

3. Monson JR, Weiser MR, Buie WD, Chang GJ, Rafferty JF, Rafferty J et al (2013) Practice parameters for the management of rectal cancer (revised). Dis Colon Rectum 56(5):535-550

4. Askari A, Nachiappan S, Currie A, Bottle A, Athanasiou T, Faiz O (2016) Selection for laparoscopic resection confers a survival benefit in colorectal cancer surgery in England. Surg Endosc 30(9):3839-3847

5. Arezzo A, Passera R, Scozzari G, Verra M, Morino M (2013) Laparoscopy for rectal cancer reduces short-term mortality and morbidity: results of a systematic review and meta-analysis. Surg Endosc 27(5):1485-1502

6. Li Y, Wang S, Gao S, Yang C, Yang W, Guo S (2016) Laparoscopic colorectal resection versus open colorectal resection in octogenarians: a systematic review and meta-analysis of safety and efficacy. Tech Coloproctol 20(3):153-162

7. Ihnát $P$, Martínek L, Mitták M, Vávra $P$, Ihnát Rudinská L, Zonča P (2014) Quality of life after laparoscopic and open resection of colorectal cancer. Dig Surg 31(3):161-168

8. Fujii S, Ota M, Ichikawa Y, Yamagishi S, Watanabe K, Tatsumi $\mathrm{K}$ et al (2010) Comparison of short, long-term surgical outcomes and mid-term health-related quality of life after laparoscopic and open resection for colorectal cancer: a case-matched control study. Int J Colorectal Dis 25(11):1311-1323

9. Bonjer HJ, Deijen CL, Haglind E, Group CIS (2015) A randomized trial of laparoscopic versus open surgery for rectal cancer. N Engl J Med 373(2):194

10. Fleshman J, Branda M, Sargent DJ, Boller AM, George V, Abbas M et al (2015) Effect of laparoscopic-assisted resection vs open resection of stage II or III rectal cancer on pathologic outcomes: the ACOSOG Z6051 randomized clinical trial. JAMA 314(13):1346-1355

11. Stevenson AR, Solomon MJ, Lumley JW, Hewett P, Clouston AD, Gebski VJ et al (2015) Effect of laparoscopic-assisted resection vs open resection on pathological outcomes in rectal cancer: the ALaCaRT randomized clinical trial. JAMA 314(13):1356-1363 
12. Nagtegaal ID, van de Velde CJ, van der Worp E, Kapiteijn E, Quirke P, van Krieken JH et al (2002) Macroscopic evaluation of rectal cancer resection specimen: clinical significance of the pathologist in quality control. J Clin Oncol 20(7):1729-1734

13. Hozo SP, Djulbegovic B, Hozo I (2005) Estimating the mean and variance from the median, range, and the size of a sample. BMC Med Res Methodol 5:13

14. Gong J, Shi DB, Li XX, Cai SJ, Guan ZQ, Xu Y (2012) Shortterm outcomes of laparoscopic total mesorectal excision compared to open surgery. World J Gastroenterol 18(48):7308-7313

15. van der Pas MH, Haglind E, Cuesta MA, Fürst A, Lacy AM, Hop WC et al (2013) Laparoscopic versus open surgery for rectal cancer (COLOR II): short-term outcomes of a randomised, phase 3 trial. Lancet Oncol 14(3):210-218

16. Jeong SY, Park JW, Nam BH, Kim S, Kang SB, Lim SB et al (2014) Open versus laparoscopic surgery for mid-rectal or lowrectal cancer after neoadjuvant chemoradiotherapy (COREAN trial): survival outcomes of an open-label, non-inferiority, randomised controlled trial. Lancet Oncol 15(7):767-774

17. Lujan J, Valero G, Hernandez Q, Sanchez A, Frutos MD, Parrilla P (2009) Randomized clinical trial comparing laparoscopic and open surgery in patients with rectal cancer. $\mathrm{Br}$ J Surg 96(9):982-989

18. Guillou PJ, Quirke P, Thorpe H, Walker J, Jayne DG, Smith AM et al (2005) Short-term endpoints of conventional versus laparoscopic-assisted surgery in patients with colorectal cancer (MRC CLASICC trial): multicentre, randomised controlled trial. Lancet 365(9472):1718-1726

19. Green BL, Marshall HC, Collinson F, Quirke P, Guillou P, Jayne DG et al (2013) Long-term follow-up of the Medical Research Council CLASICC trial of conventional versus laparoscopically assisted resection in colorectal cancer. Br J Surg 100(1):75-82

20. Braga M, Frasson M, Vignali A, Zuliani W, Capretti G, Di Carlo V (2007) Laparoscopic resection in rectal cancer patients: outcome and cost-benefit analysis. Dis Colon Rectum 50(4):464-471

21. Ng SS, Lee JF, Yiu RY, Li JC, Hon SS, Mak TW et al (2014) Laparoscopic-assisted versus open total mesorectal excision with anal sphincter preservation for mid and low rectal cancer: a prospective, randomized trial. Surg Endosc 28(1):297-306

22. Ng SS, Leung KL, Lee JF, Yiu RY, Li JC, Teoh AY et al (2008) Laparoscopic-assisted versus open abdominoperineal resection for low rectal cancer: a prospective randomized trial. Ann Surg Oncol 15(9):2418-2425

23. Ng SS, Leung KL, Lee JF, Yiu RY, Li JC, Hon SS (2009) Longterm morbidity and oncologic outcomes of laparoscopic-assisted anterior resection for upper rectal cancer: ten-year results of a prospective, randomized trial. Dis Colon Rectum 52(4):558-566

24. Kang SB, Park JW, Jeong SY, Nam BH, Choi HS, Kim DW et al (2010) Open versus laparoscopic surgery for mid or low rectal cancer after neoadjuvant chemoradiotherapy (COREAN trial): short-term outcomes of an open-label randomised controlled trial. Lancet Oncol 11(7):637-645

25. Martínez-Pérez A, Carra MC, Brunetti F, de'Angelis N (2017) Pathologic outcomes of laparoscopic vs open mesorectal excision for rectal cancer: a systematic review and meta-analysis. JAMA Surg 152(4):e165665

26. Abbas SK, Yelika SB, You K, Mathai J, Essani R, Krivokapić Z et al (2017) Rectal cancer should not be resected laparoscopically: the rationale and the data. Tech Coloproctol 21(3):237-240

27. Rullier A, Gourgou-Bourgade S, Jarlier M, Bibeau F, ChassagneClément C, Hennequin C et al (2013) Predictive factors of positive circumferential resection margin after radiochemotherapy for rectal cancer: the French randomised trial ACCORD12/0405 PRODIGE 2. Eur J Cancer 49(1):82-89

28. Nagtegaal ID, Marijnen CA, Kranenbarg EK, van de Velde CJ, van Krieken JH, Committee PR et al (2002) Circumferential margin involvement is still an important predictor of local recurrence in rectal carcinoma: not one millimeter but two millimeters is the limit. Am J Surg Pathol 26(3):350-357

29. Deijen CL, Velthuis S, Tsai A, Mavroveli S, de Lange-de Klerk ES, Sietses C et al (2016) COLOR III: a multicentre randomised clinical trial comparing transanal TME versus laparoscopic TME for mid and low rectal cancer. Surg Endosc 30(8):3210-3215

30. Li J, Guo H, Guan XD, Cai CN, Yang LK, Li YC et al (2015) The impact of laparoscopic converted to open colectomy on shortterm and oncologic outcomes for colon cancer. J Gastrointest Surg 19(2):335-343

31. White I, Greenberg R, Itah R, Inbar R, Schneebaum S, Avital S (2011) Impact of conversion on short and long-term outcome in laparoscopic resection of curable colorectal cancer. JSLS 15(2): 182-187

32. Allaix ME, Furnée EJ, Mistrangelo M, Arezzo A, Morino M (2016) Conversion of laparoscopic colorectal resection for cancer: what is the impact on short-term outcomes and survival? World J Gastroenterol 22(37):8304-8313

33. Shaw A, Collins EE, Fakis A, Patel P, Semeraro D, Lund JN (2008) Colorectal surgeons and biomedical scientists improve lymph node harvest in colorectal cancer. Tech Coloproctol 12(4):295-298. doi:10.1007/s10151-008-0438-2

34. Mekenkamp LJ, van Krieken JH, Marijnen CA, van de Velde CJ, Nagtegaal ID, Investigators PRCatC-oC (2009) Lymph node retrieval in rectal cancer is dependent on many factors-the role of the tumor, the patient, the surgeon, the radiotherapist, and the pathologist. Am J Surg Pathol 33(10):1547-1553

35. Parmar MK, Torri V, Stewart L (1998) Extracting summary statistics to perform meta-analyses of the published literature for survival endpoints. Stat Med 17(24):2815-2834

36. Etzioni DA, Young-Fadok TM, Cima RR, Wasif N, Madoff RD, Naessens JM et al (2014) Patient survival after surgical treatment of rectal cancer: impact of surgeon and hospital characteristics. Cancer 120(16):2472-2481

37. Aquina CT, Probst CP, Becerra AZ, Iannuzzi JC, Kelly KN, Hensley BJ et al (2016) High volume improves outcomes: the argument for centralization of rectal cancer surgery. Surgery 159(3):736-748

38. Baek JH, Alrubaie A, Guzman EA, Choi SK, Anderson C, Mills S et al (2013) The association of hospital volume with rectal cancer surgery outcomes. Int J Colorectal Dis 28(2):191-196 